\title{
Yabancı Bankaların Bankacılık Sektörü Aktif Kârlıı̆ı̆ı Üzerindeki Etkileri: BRICS-T Örneği ${ }^{1}$ \\ Erkan SARSICI ${ }^{2}$ İbrahim Halil EKŞi ${ }^{3}$
}

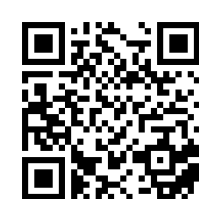

\begin{tabular}{ccc}
\hline Geliş Tarihi/ Received & Kabul Tarihi/ Accepted & Yayın Tarihi/ Published \\
31/01/2020 & $15 / 05 / 2020$ & $15 / 07 / 2020$ \\
\hline Citation/Atıf: Sarsıcı, E. ve Ekşi, I. H., (2020), Yabancı Bankaların Bankacılık Sektörü Aktif \\
Kârlılığı Üzerindeki Etkileri: BRICS-T Örneği , Atatürk Üniversitesi İktisadi ve İdari Bilimler \\
Dergisi, 34(3): Sayfa: 669-687, DOI: 10.16951/atauniiibd.682815 \\
\hline
\end{tabular}

Öz: Finansal piyasalarda rekabetin artması ve finansal serbestleşmenin hız kazanması nedeniyle bankalar uluslararasılaşma yoluna giderek, daha fazla kar ve daha fazla müşteriye sahip olabilmek için yeni pazarlara açılmayı tercih edebilmektedirler. Yabancı banka şeklinde ortaya çıkan bu olgu, son yıllarda özellikle gelişmekte olan ülkelerde kendilerini göstermektedir. Gelişmekte olan ülkeler olarak değerlendirilen BRICS-T ülkeleri sahip oldukları nüfus ve ekonomik nedenlerle yabancı bankaların risk iştahını arttıran bir grup olarak görülmektedir.

Bu çalışmada 2006-2016 yılları arası BRICS (Brezilya, Rusya, Hindistan, Çin ve Güney Afrika) ve Türkiye'deki yabancı bankaların varlığının bankacılık sektörü üzerindeki etkisi incelenmeye çalışılmıştır. Bu bağlamda, Aktif Kârlılık Oranı (ROA) bağımlı değişken; Enflasyon, Büyüme, Mevduat, Net Faiz Marjı ve Yabancı Banka Aktifleri oranları da bağımsız değişken olarak kabul edilip, dengeli panel veri yöntemi kullanılmıştır. Aktif kârlılık oranına, yabancı banka aktifleri, net faiz marjı ve büyümenin pozitif etkisinin olduğu sonucuna ulaşılmıştır.

Anahtar Kelimeler: BRICS, Yabancı banka, Aktif Kârlılık, Panel veri

Effects of Foreign Banks on the Profitability of Banking Sector Assets: BRICS-T Example Abstract: Due to the increase in competition in financial markets and the acceleration of financial liberalization, banks may prefer to open to new markets in order to gain more profit and more customers by going to internationalization. This phenomenon, which emerged as a foreign bank, has been manifested in recent years, especially in developing countries. BRICS-T countries, which are considered as developing countries, are seen as a group that increases the risk appetite of foreign banks due to their population and economic reasons.

In this study, between the years 2006-2016 BRICS (Brazil, Russia, India, China and South Africa) and its effect on the banking sector of the presence of foreign banks in Turkey have been

${ }^{I}$ Bu çalışma Halil İbrahim EKŞİ danışmanlığında Hasan Kalyoncu Üniversitesi Sosyal Bilimler Enstitüsünde yürütülen Erkan SARSICI'nın "Yabancı Bankaların Reel Sektöre Verilen Krediler Ve Bankacılık Sektörü Kârlılığı Üzerindeki Etkileri: BRICS-T Örneği” başlıklı doktora tezinden türetilmiștir.

${ }^{2}$ Dr. Adryaman Üniversitesi, Besni Meslek Yüksekokulu, Bankacıllk ve Sigortacıllk Bölümü, https://orcid.org/0000-0002-8719-9205

${ }^{3}$ Prof. Dr. Gaziantep Üniversitesi, İktisadi ve İdari Bilimler Fakültesi, İșletme Bölümü, https://orcid.org/0000-0002-0239-3253 
studied. In this context, Active Profitability Rate (ROA) dependent variable; Inflation, Growth, Deposits, Net Interest Margin and Foreign Bank Asset rates are also accepted as independent variables and balanced panel data method is used. It was concluded that the asset profitability ratio has a positive effect on foreign bank assets, net interest margin and growth.

Key Words: BRICS, Foreign bank, Asset profitability, Panel data

\section{Introduction}

\section{EXTENDED ABSTRACT}

In this study, between the years 2006-2016 BRICS (Brazil, Russia, India, China and South Africa) and its effect on the banking sector of the presence of foreign banks in Turkey it has been studied. In this context, Active Profitability Rate (ROA) dependent variable; Inflation, Growth, Deposit, Net Interest Margin and Foreign Bank Assets ratios are also considered as independent variables and balanced panel data method is used. It was concluded that the return on assets ratio, foreign bank assets, net interest margin and growth had a positive effect.

Banks, one of the most important actors of international economic and financial relations, played an important role in the globalization process by exhibiting an outward opening movement. Financial liberalization was ensured and banks were able to stand out from local markets and integrate into the markets of developing countries. Foreign banks entering the markets of developing countries have brought competition in the local banking sector to an international dimension.

With globalization, foreign capital has been accelerating towards developing countries. With the inclusion of foreign banks with global capital into the banking sectors of developing countries, the level of competition in the banking sectors of developing countries increased. Therefore, the diversity of products in the banking sector has increased simultaneously.

A wider global financial liberalization has become attractive to banks for banks to grow more commercially and economically. With the liberalization, the financial sector will have the opportunity to grow. Therefore, before embarking on international banking activities of foreign banks, they should investigate the positive and negative aspects of the local banking sector and take into account financial liberalization and the level of liberalization in different parts of the world. Restrictions received by the national authorities regarding the stages of entry into the country, the amount of capital imposition, reserve deposits and profit transfers may support or prevent foreign banks from investing in these countries.

In the application part of the study, whether there is an effect between the assets of foreign banks in BRICS-T countries and the asset profitability ratio of the banking sector and if there is a relationship, the direction of this relationship is investigated. The existence of this relationship was analyzed by using panel data analysis method based on annual data for 2006-2016 period. 
In this study investigating the effects on the banking system of foreign banks, the banks in BRICS countries and Turkey, are discussed in the annual data for the 2006-2016 period.

Although foreign banks have different effects on the banking sector of the country, the effect of foreign banks on the profitability of the banking sector will be tested in this study. ROA, which is frequently used in the literature (Classens, 2001; Balaj, 2010; Azam, 2012; Arshad, 2012; Baltac1, 2012) will be used to represent the banks' return on assets.

\section{Conculusion}

According to the results of the analysis, a positive and significant relationship between ROA and foreign bank assets was determined as $10 \%$. Each 1\% increase in foreign bank assets leads to an increase of $0.046 \%$ on the asset profitability of banks. It was determined that there is a positive and significant relationship between the ratio of foreign bank assets to sector assets and the profitability of bank assets.

With the increase in inflation, a negative relationship is expected between banks' return on assets. In the event of high inflation, the decrease in bank profits due to the postponement of consumption and the decrease in transactions with the bank is normally acceptable. However, the test results show that there is a meaningful relationship between inflation and bank asset profits.

It is seen that there is a significant and positive relationship between the two variables (ROA and NFM) with a coefficient of 0.231 at the level of $1 \%$. Each $1 \%$ increase in net interest margin leads to an increase of $0.231 \%$ on the asset profitability of banks. If the net interest margin increases, there will be increases in bank asset profits. It is expected that the net interest margin will increase, banks will borrow with low interest rates, and they will make more profit due to lending funds borrowed with higher interest rates. For these reasons, a positive relationship between the net interest margin and the return on assets of the bank is common. A positive and significant relationship was found between net interest margin and bank asset profitability. Arshad (2012) and the findings obtained in our study support each other.

Again, there is a meaningless relationship between ROA and GDP. A positive correlation between GDP and asset profitability of banks is expected. If the growth trend of the countries' banking system continues, bank profits are likely to increase due to economic growth. With the growth, it is expected that the banks will have more opportunities to find more funds and it is expected that these funds will be evaluated and turned into more profit. However, as a result of the analysis, it was found that there was no meaningful relationship between ROA and GDP. No significant relationship was found between the return on assets and growth. 
Yabancı Bankaların Bankacılık Sektörü Aktif Kârlllı̆̆ı Üzerindeki Etkileri: BRICS-T Örneği

\section{Giriş}

Uluslararası ekonomik ve finansal ilişkilerin en temel aktörlerinden biri olan bankalar dışa açılım hareketi sergileyerek, küreselleşme sürecinde önemli bir rol oynamıştır. Finansal liberalizasyonun sağlanması ve bankaların yerel piyasalardan sıyrılıp gelişmekte olan ülke piyasalarına entegre olması sağlanmıştır. Gelişmekte olan ülkelerin piyasalarına giren yabancı bankalar, yerel bankacılık sektöründeki rekabeti uluslararası boyuta taşımıştır.

Küreselleşme ile beraber yabancı sermayelerin gelişmekte olan ülkelere doğru seyir izlemesi hız kazanmıştır. Küresel sermayeli yabancı bankaların gelişmekte olan ülkelerin bankacılık sektörlerine dâhil olması ile gelişmekte olan ülkelerin bankacılık sektörlerindeki rekabet düzeyi artmıştır. Bundan dolayı eş zamanlı olarak bankacılık sektöründeki ürün çeşitliliği çoğalmıştır.

Küresel finansal liberalleşme, bankalar için daha fazla ticari ve ekonomik büyümeyi ifade ettiği için bankalar tarafından cazip karşılanmıştır. Liberalleşme ile birlikte finansal sektör büyüme imkânı bulacaktır. Bu nedenle yabancı bankalar diğer ülke bankacılık faaliyetlerine katılmadan önce, uluslararası bankacılık alanında yaşanabilecek olumlu ve olumsuz yönleri araştırmalıdırlar. Ülkeye giriş aşamaları, sermaye koyma zorunluluk miktarı, rezerv mevduat ve kâr transferleri ile ilgili ülke otoritelerinin aldığı kısıtlamalar, yabancı bankaların bu ülkelere yatırım yapmalarına destek ve ya engel olabilmektedir.

Finansal piyasalar içinde en büyük paya sahip olan bankaların kredi, fon ve mevduat yöntemleri ile piyasalara önemli katkıları olmaktadır. Zira Türkiye'de finans piyasalarının aktif büyüklüğünün \%82'lik kısmını bankalar oluşturmaktadır (BDDK, 2018: 15).

Temelde, kredi sağlama, mevduat toplama ve aracilık olarak sinıflandırılabilecek bankacılık sektörünün piyasa üzerindeki etkisini belirleyen birçok faktör söz konusudur. Bu faktörlerden birisi de bankaların sahiplik yapısı ve buna bağlı olarak bankalarda yabancı sahipliğidir. Genel olarak yabancı bankalar literatürde, hisselerinin \%50'sinden fazlası yabanc1ların elinde olan bankalar olarak tanımlanmaktadır (Bumin, 2007: 7).

Ulusal bankacılık sektöründe yabancı sermayeli bankaların faaliyet göstermesinin bankacılık sektörü üzerinde etkisi, uzun zamandır literatürde araştırılmaktadır (Grosse, 1991; Leung, 1997; Denizer, 1999; Claessens vd., 2001). Bu çalışmaların özellikle gelişmekte olan ülkelerde ve geçiş ekonomilerinde (Çin, Brezilya, Macaristan, Makedonya, Polonya v.d.) yoğunlaştığı gözlemlenmektedir (Hefferman, 2005; Yavuz ve Akgeyik, 2009; Bain ve diğerleri, 1999; Mathieson ve Roldos, 2001; Şahözkan, 2003; Baltac1, 2011).

Yabancı banka varlıklarının söz konusu ülkelerde artış göstermesinin birçok nedeni olmakla beraber, bunların içinde ekonomik büyüme, müşteri sayısı, hizmet ve gelir miktarını artırma hedefleri gibi nedenler daha ağır basmaktadır (Claessens ve diğerleri 2001: 892). 
Yükselen piyasa ekonomileri olarak da bilinen BRICS-T ülkelerinin ortak temel özellikleri teknolojik altyapının hızlı ilerlemesi, nüfusun hızlı bir şekilde artması, genç nüfus yoğunluğunun yüksek olması, yer altı kaynaklarının zengin olması, işgücü veriminin, teknik ve donanımlı yöneticilerinin fazla olması, yüksek büyüme oranları olarak sıralanabilir (Özsoylu ve Algan, 2011: 2). Sayılan bu özellikler sayesinde üretim maliyetleri ve ücretler düşük olmakta, bu sebeple yabancı yatırımcıların risk iştahı artarak yatırım yapmakta ve döviz girdisi oluşmaktadır. Dolayısıyla artan üretim sayesinde ihracat ve buna bağlı olarak da milli gelir artmaktadır (Afşar, 2004: 90).

Küresel düzeyde 2008-2017 tarihleri arasında kişi başına düşen GSMH' nın yıllık büyüme hızı ortalaması \%1.7 olarak açıklanmıştır. Fakat BRICS ülkeleri aynı dönemde, \%5.4'lük bir ortalama büyüme ile kişi başına küresel büyümenin ana itici güçleri olmuştur. Genel olarak bakıldığında, BRICS grubu dünya GSMH' nın \%30.4'ünü oluşturmaktadır (www.ineteconomics.org). BRICS ülkeleri ile benzer ekonomik rakamlara (büyüme, enflasyon, yabancı banka aktif payları ve aktif kârlılık oranı ) sahip Türkiye'de de yabancı banka varlıklarının ülke ekonomisine ve ülke bankacılık sistemine olan etkileri gündemdeki yerini korumaktadır. Konuyla ilgili olarak literatürde daha önce yapılan çalışmalar olmakla birlikte (Arshad, 2012; Sarı, 2018; Foundation, 2015) BRICS ülkeleri ile Türkiye'nin birlikte ele alındığı çalışmalara rastlanılmamıştır.

Çalışma, literatür araştırması, BRICS-T ülkeleri ve bu ülkelerdeki bankacılık sistemi hakkında bilgiler ve uygulama bölümü şeklinde devam etmektedir.

\section{Literatür Araştırması}

Literatürde yabancı bankaların ülke bankacılık sistemi üzerindeki etkileri konusunda farklı çalışmalar yapıldığg görülmektedir. Söz konusu çalışmalarda, yabancı bankaların etkileri konusunda farklı sonuçlara ulaşılmıştır. Yabancı bankaların ülke bankacılık sektörünün karına olan olumlu etkileri üzerine (Clarke ve diğerleri, 2002; Goldberg ve diğerleri, 2000; Magri ve diğerleri, 2005; Chantapong, 2005; European Bank, 2017) yapılan bazı çalışmalar gözlemlenmiştir. Diğer bazı çalışmalarda (Gopalan ve Rajan, 2017; Arshad, 2012; Yayla ve diğerleri, 2006; Claessens ve Horen, 2014), olumsuz etki gözlemlenmiştir. Bazı çalışmalarda ise (Sanyal ve Shankar, 2011; Fungacova ve Poghosyan, 2011; Aktaş ve Kargın, 2007) yabancı bankaların ülke ekonomisi üzerinde etkisine rastlanılmamıştır.

$\mathrm{Bu}$ çalışmalardan öne çıkanları aşağıda açıklanmıştır:

Claessens ve arkadaşları (2001), 1988-1995 yılları arasında dünyanın 80 gelişmekte olan ve gelişmiş ülkesinde faaliyet gösteren 7900 bankayı temel almışlardır. Regresyon analizi yöntemini kullandıkları araştırmalarında, yabancı bankaların iç pazara girişlerini, bankaların kârlılıklarını, bankaların performans ve verimliliklerini artırdıklarını ortaya koymuşlardır. 

Örneği

Clarke ve arkadaşları (2002), geçiş ekonomisine sahip ve gelişmekte olan 36 ülkede, 1999 yılı verileri kullanılarak yaklaşık 3000 işletme üzerine çalışma gerçekleştirmiştir. Yapılan çalışmada yabancı banka girişlerinin artması nedeniyle firmaların bankalardan daha fazla destek alabildiği ve bu neticede bankaların kârlarına katkı sağladıkları sonucuna varılmıştır.

Chantapong (2005), çalışmasında Tayland'daki yabancı bankaların Doğu Asya'daki finansal krizden sonra kârlılık ve diğer özellikleri yönünden performansını incelemiştir. Çalışma, 1995-2000 yılları arasında Tayland'daki yerli ve yabancı bankaların ana bilanço ve gelir tablosu oranları ile bankalar aras1 verilerini bir araya getirerek finansal tablolar hakkında panel veri analizine dayanmaktadır. Araştırma bulgularına göre, tüm bankaların yabancı banka artışından sonra kârlılıklarını kademeli olarak artırdı ̆̆ı tespit edilmiştir.

Baltacı (2011) çalışmasında, 1995-2008 döneminde geçiş ekonomilerindeki yabancı banka varlığı ile kredi tahsisi arasındaki ilişkiyi incelemiştir. Çalışmada panel veri yöntemini kullanmıştır. Çalışma sonucundan yabancı banka varlığı ile özel sektöre verilen krediler arasındaki ilişkileri yorumlamıştır. Geçiş ekonomilerinde yabancı banka varlığının kredilere erişimi makro boyutta olumlu etkilediği bulgularına ulaşmıştır.

Rokhim ve Susanto (2013), çalışmalarında Endonezya'da faaliyet gösteren 115 ticari bankanın 2003-2008 yılların arasındaki verilerini temin ederek analiz etmişler ve yabancı bankaların piyasaya girişleri ile bankacılık sektörü üzerindeki kârlılık ve maliyet etkinliğini araştırmışlardır. Araştırma sonucuna göre yabancı bankaların piyasaya girmesi ile rekabetin arttığı, maliyetin düştüğü ve bankacılık kârının arttığı sonuçlarına ulaşmışlardır.

Boadi (2015), çalışmasında yabancı banka girişlerinin Gana'daki bankaların faaliyetlerine olan etkilerini incelemiştir. Çalışmada panel veri analizi kullanmıştır. Çalışmada 1997-2014 dönemine ait verileri kullanmıştır. Çalışmanın sonucunda, yabancı bankaların varlığı ile banka aktif kârlılı̆ğ, net faiz geliri ve GSYİH büyümesi arasında istatistiksel olarak anlamlı bir ilişkinin olduğu görülmüştür. Ancak, yabancı bankalar; likidite, mevduat oranı, takipteki krediler, çalışan sayısı ve enflasyonu önemli ölçüde etkilemediği sonucuna ulaşılmıştır.

\section{BRICS-T Ülkelerinde Yabancı Bankalar}

Globalleşen dünya şartlarında daha fazla kâr elde etmek isteyen bankalar ülke sınırları dışına çıkarak kârlarını maksimum düzeye çıkarmayı hedeflemektedirler. $\mathrm{Bu}$ da kendisini yabancı banka şeklinde göstermektedir. Finansal liberalleşmenin hız kazanması ile yapılan düzenlemeler sayesinde bankalardaki yabancı sermaye sınırlaması gelişmekte olan ülkelerde kaldırılarak yabancı bankaların önemi ve sayısı daha fazla artmıştır. Yaşanan bu gelişmeler sayesinde geçiş ekonomileri ve gelişmekte olan ülkelerde yabancı banka girişlerinde ve banka rekabetlerinde bir artış yaşanmıştır (Şahözkan, 2003: 254). 
Yabancı bankaların faaliyet alanları küreselleşme ile birlikte daha da genişlemeye başlamıştır. Yabancı bankalar diğer ülke piyasalarına 1980 ve 1990'lı yıllarda girmeye başlamıştır. Bu y1llarda serbestleşme politikaları ile birlikte, yabancı banka şubelerinin açılması, teknoloji transferi ve üretiminin artmas1, sermaye ve bilgi transferi gibi birçok yeni hizmetlerin gelişmesi de sağlanmıştır. Sektör içindeki yabancı banka paylarının hızlı bir biçimde yükselmeye başladığı ve yapısal değişikliklere neden olduğu görülmüştür (TBB, 2005: 3).

Yabancı bankaların bankacılık hizmetleri işlemlerini yapabilmesi için, fiziki olarak aracılık yapacağı ülke sınırları kapsamında bulunması şart değildir. Diğer bir anlatımla, bir banka uluslararası bankacılık faaliyetlerini, diğer ülkelerde anlaşmış olduğu yerli bankalar (rambursman veya muhabir banka) aracılığıyla, uluslararası ödemeler sistemi vb. yöntemler kullanarak da gerçekleştirebilir (Baltac1, 2011: 16).

BRICS ülkeleri ve Türkiye'deki faaliyette bulunan yabancı bankaların sayısının ülkede bulunan toplam banka sayısına oranı hakkında detaylı bilgi Tablo 1'de verilmiştir.

Tablo 1: Yabancı Bankaların Sayısının Bankacılık Sektörü İçerisindeki Payı (\%)

\begin{tabular}{|l|l|l|l|l|l|l|l|}
\hline Ülke & Brezilya & Çin & Hindistan & Rusya & G. Afrika & Türkiye & $\begin{array}{l}\text { BRICS-T } \\
\text { Ortalama }\end{array}$ \\
\hline $\mathbf{2 0 0 6}$ & 35 & 6 & 11 & 15 & 22 & 34 & 20,5 \\
\hline $\mathbf{2 0 0 7}$ & 36 & 15 & 11 & 17 & 22 & 39 & 23,3 \\
\hline $\mathbf{2 0 0 8}$ & 38 & 18 & 12 & 20 & 23 & 39 & 25 \\
\hline $\mathbf{2 0 0 9}$ & 37 & 19 & 12 & 20 & 23 & 39 & 25 \\
\hline $\mathbf{2 0 1 0}$ & 38 & 21 & 12 & 20 & 24 & 39 & 25,6 \\
\hline $\mathbf{2 0 1 1}$ & 38 & 21 & 12 & 19 & 24 & 36 & 25 \\
\hline $\mathbf{2 0 1 2}$ & 39 & 20 & 12 & 18 & 24 & 35 & 24,6 \\
\hline $\mathbf{2 0 1 3}$ & 40 & 20 & 12 & 17 & 24 & 38 & 25,1 \\
\hline $\mathbf{2 0 1 4}$ & 40 & 21 & 13 & 17 & 24 & 38 & 25,5 \\
\hline $\mathbf{2 0 1 5}$ & 41 & 21 & 13 & 18 & 24 & 40 & 26,1 \\
\hline $\mathbf{2 0 1 6}$ & 41 & 21 & 13 & 18 & 24 & 40 & 26,1 \\
\hline
\end{tabular}

Kaynak: http:/data.worldbank.org/indicator, 2019

Tablo 1 incelendiğinde en yüksek yabancı sahiplik oranına sahip olan ülkelerin Brezilya ve Türkiye olduğu görülmektedir. Bu ülkelerde bulunan yabancı bankaların toplam bankacılığın neredeyse yarısına yakın bir oranına sahip olduğu görülmektedir. En az orana sahip olan ülkelerin ise Hindistan ve Rusya olduğu görülmektedir.

Yabancı banka girişlerinin bankacılık sektörüne olumlu ve olumsuz etkileri olabilmektedir. Bu etkilerden olumlu olanları (Bonin ve diğerleri, 1998; Dages ve diğerleri, 2000);

Yabancı bankalar, yeni bankacılık teknolojisi ve finansal piyasalara mali yenilikler getirmektedir. Ülkenin makroekonomik durumu yabancı bankaların, 
bankacılık sistemine dâhil olmasını teşvik etmeye yardımcı olabilir. Bankacılık piyasasında rekabetin gelişimine katkıda bulunur. Mali piyasaların gelişimine katkı sağlar. Mali sistemin altyapısının gelişimine yön verir. Yabancı bankalar doğrudan yabancı sermaye yatırımlarını bulundukları ülkelere çekerler.

Yabancı banka girişlerinin olumsuz etkileri ise (Erdönmez, 2004: 22, Anderson ve Kegels, 1998: 65);

Yabancı bankaların rekabeti nedeniyle kısa dönemde yerel bankalar sıkıntıya düş̧ebilir. Yabancı sermayeli bankalar ulusal bankalara göre farklı önceliklere sahip olduklanı için, ülke çıkarlarına çok fazla esnek davranmak istemeyeceklerdir. Yabancı sermayeli bankalar sektörde büyük bir paya sahip iseler, müşterilerine kredi verecekleri zaman, daha kârlı, bilançoları sağlam ve büyük müşterileri seçerek ayrımcılık yapabileceklerdir. Bu durumda, küçük ve yerel firmalar tercih edilmediği için kredi bulmakta zorlanabileceklerdir. Yabancı bankalar kendi ülkelerindeki ekonomik sıkıntılar sebebiyle yatırım yaptıkları ülkeden çekilerek, yerel bankacılık sektörünü sıkıntıya sokabilirler. Yerel para ve finansal denetleme otoritelerinin, risk yönetimi ve stratejik kararlar alırken temel fonksiyonlarında bilgi ve kontrol eksikliğine neden olabilirler.

\section{Uygulama}

Çalışmanın uygulama bölümünde BRICS-T ülkelerindeki yabancı bankaların aktifleri ile birlikte bankacılık sektörünün aktif kârlılık oranı arasında bir etkinin olup olmadığı, ilişki varsa bu ilişkinin yönü araştırılmıştır. $\mathrm{Bu}$ ilişkinin varlığı, panel veri analizi yöntemi kullanılarak 2006-2016 dönemine ilişkin yıllık veriler baz alınarak analiz edilmiştir.

\section{Panel Veri Analiz Yöntemi;}

Panel veri analiz yöntemi, ülkeler, firmalar, hane halkları ya da birimlere ait yatay ve zaman kesitlerindeki çeşitli gözlemlerin havuzlanması (pooling) olarak ifade edilebilir (Baltagi, 2001: 1). Yatay kesit ve zaman serisi verilerinin bileşiminden oluşan panel veriler, karma veri veya dikey (longitudinal) veri olarak da adlandırılmaktadır (Güriş ve Çağlayan, 2005: 9).

\section{Panel Veri Modelleri,}

Panel veri modelleri teorik yazına göre statik ya da dinamik model olarak iki ana grup halinde incelenebilir. Statik panel verilerde modele dâhil olan değişkenlerin geçmiş değerleri modele dâhil edilmezken dinamik panel verilerde modele dâhil olan değişkenlerin geçmiş değerleri modele dâhil edilir.

Panel veri modeli yapilarak varılan analiz sonucunda hata terimlerinin birimlere göre bağımsız olduğu varsayılmaktadır. Bu durum ise analizlerin hatalı sonuçlar vermesine sebep olmaktadır. Seriler arasında yatay kesit bağımlılığının varlığı halinde bu durum dikkate alınmadan yapılacak bir analizde elde edilecek sonuçlar önemli derecede etkilenmektedir (Breusch ve Pagan, 1980; Pesaran, 2004). 
Durağan olmayan veriler, yapısal kırılmalar veya birim kök içeren stokastik bir süreç şeklinde gösterilmektedir. Birim kökler, serilerin durağan olmamasına sebep olabilen en önemli etkenlerden biridir. Ancak, birim kök içermeyen bir analizin durağan olduğunu söylemek mümkündür. Durağan olmayan değişkenler en küçük kareler modelinde kullanıldığı durumlarda, bu modelin tahmin edilmesinde kullanılan F-istatistiği, t-istatistiği, $\mathrm{R}^{2}$ değeri dibi değerler sonuca yönelik yanıltıcı rakamlar verebilmektedir. Panel veri analizlerinde, genellikle değişkenlerin birinci farkların alındığı durumlarda sonuç durağan olabilmektedir. Fakat birinci farkları alınan değişkenlerin regresyon yapılan analizlerde kullanılması durumlarında, bu değiş̧kenlerin uzun vadede aralarındaki ilişki ve özellikler kaybolabilmektedir (Nkoro ve Uko, 2016: 68).

Sabit Etkiler Modeli;

Sabit etkiler modeli denklemi aşağıda ki gibi gösterilebilir:

$$
y_{i, t}=\alpha_{i}+\beta_{1, i} x_{1 i, t}+\beta_{2 i} x_{2 i, t}+\cdots+\beta_{M i} x_{M i, t}+e_{i, t}
$$

Burada; $i=1, \ldots ., N, \quad t=1, \ldots ., T$ ve $\alpha_{\mathrm{i}}$ yatay kesit boyunca değişen fakat zaman boyunca değişmeyen bir sabit katsayıdır. Bu katsayı aynı zamanda birime ait ortalamayı da temsil eder. Bu denklemde $\alpha_{\mathrm{i}}=\alpha+\gamma_{\mathrm{i}}$ şeklinde yazılabilir. $\sum_{i=t}^{N} \gamma_{i}=0$ olmak üzere, $\gamma_{i}$ ifadesi genel ortalama $\alpha$ 'dan sapmaları gösterir. $e_{\mathrm{it}}$ $\sim N\left(0, e_{i, t} \sim N\left(0, \sigma_{e}^{2}\right)\right.$ olan tesadufi değişkendir. Burada model eğim parametrelerinin tahmin edicisi,

$$
\hat{\beta}_{F E}=\frac{\sum_{i=1}^{N} \sum_{t=1}^{T}\left(x_{i, t} \bar{x}_{i}\right)\left(y_{i, t-} \bar{y}_{i}\right)}{\sum_{i=1}^{N} \sum_{t=1}^{T}\left(x_{i, t_{-}} \bar{x}_{i}\right)\left(x_{i, t_{-}} \bar{x}_{i}\right)^{2}}
$$

olarak yazılır. Bu tahmin edici, grup içi tahmin edicisi olarak adlandırılır.

Sabit etkiler modelinin geçerli olup olmadığını test eden ilk yöntem $F_{H_{01}}$ testidir.

$$
F_{H_{01}}=\frac{\left(K K T_{R}-K K T_{u n}\right) / k l s i t \text { sayıs }}{K K T_{u n} / s d}
$$

Burada $K K T_{R}$, kısıtlanmış modelin kalıntılarını ifade etmektedir. $K K T_{u n}$ ise kısıtlanmamış modelin kalıntılarını ifade etmektedir.

$F_{H 01}$ yönteminin hipotez testi aşağıdaki gibidir:

F Testi anlamlı ise, boşluk hipotezi ret edilir ve sabit etkiler havuzlanmış modele göre tercih edillir.

Tesadüfi Etkiler Modeli;

Tesadüfi etkiler modeli aşağıdaki gibi ifade edilebilir:

$$
y_{i}=\alpha_{i}+\beta_{1 i} x_{1 i}+\beta_{2 i} x_{2 i} \ldots \ldots \ldots \ldots+\beta_{M i} x_{M i}+e_{i, t}
$$

Burada $\alpha_{i}, \quad \alpha_{1}$ ortalama değeriyle bir tesadüfi değişken olarak varsayılmıştır. Yani bir birimin sabit katsayısının değeri aşağıdaki şekilde ifade edilir

$$
\alpha_{i}=\alpha_{1}+u_{i} \quad i=1,2,3, \ldots \ldots \ldots \ldots
$$



Örneği

Burada $u_{i}$ sıfir ortalamalı ve $\sigma_{\mathrm{u}}^{2}$ varyanslı tesadüfi hata terimidir. $\alpha_{i}=\alpha_{1+}$ $u_{i}$ ifadesi yerine konulursa;

$$
\begin{aligned}
& y_{i}=\alpha_{1}+\beta_{1 i} x_{1 i}+\beta_{2 i} x_{2 i} \ldots \ldots+\beta_{M i} x_{M i}+u_{i}+e_{i, t} \\
& y_{i}=\alpha_{1}+\beta_{1 i} x_{1 i}+\beta_{2 i} x_{2 i} \ldots \ldots+\beta_{M i} x_{M i}+w_{i}+e_{i, t}
\end{aligned}
$$

olarak yazılır ve burada $w_{i, t}$ iki bileşenden oluşan birleşik hata terimidir. Birime özgü hata terimi $u_{i}$ ve zaman serisi ile kesitin birleşimi sonucu oluşan hata terimi $e_{i, t}$ 'dir.

Sabit etki ile tesadüfi etki arasındaki fark önemlidir. Sabit etki modelinde $\alpha_{1}$ sabiti bütün birimlerin ortalama parametresidir. Dolayısıyla tesadüfi etki modelindeki $u_{i}$ hata bileşeni birime özgü sabitin bu ortalama değerden tesadüfi sapmalarını göstermektedir. $u_{i}$ doğrudan gözlenemeyen bir değerdir (Baltagi, 2005: 15).

\section{Hausman Testi;}

Hausmann (1978) tarafından geliştirilen bu test, gözlenemeyen etkiler $v_{i}$ ile açılayıcı değişkenler arasındaki korelasyonun incelenmesine dayanır. Bir başka ifadeyle içsellik sorununu test etmektedir. Ayrıca, bu test sabit etkiler modeli ile rassal etkiler modeli arasında tercih yapmaya olanak sağlamaktadır.

Bu test, $\chi^{2}$ dağılımına sahiptir. Bu teste ilişkin hipotezler aşağıdaki şekilde yazılabilir:

$$
\begin{array}{ll}
H_{0}: E\left(v_{i} \mid \bar{x}_{i, t}\right)=0 & \text { Gözlenemeyen etkiler yoktur. } \\
H_{1}: E\left(v_{i} \mid \bar{x}_{i, t}\right) \neq 0 & \text { Gözlenemeyen etkiler vardır. }
\end{array}
$$

Modelde, $\mathrm{i}=1,2, \ldots, \mathrm{N}$ kesit birimini ve $\mathrm{t}=1,2, \ldots \ldots, \mathrm{T}$ de zaman dönemini göstermektedir. Vi gözlemlenemeyen zaman etkisi, Xit geçiş hata terimini göstermektedir.

\section{Veri Seti ve Model}

Yabancı bankaların ülke bankacılık sistemi üzerindeki etkilerini araştıran bu çalışmada, BRICS ülkeleri ile Türkiye'deki bankaların, 2006-2016 periyodunda yıllık verileri ele alınmıştır.

Yabancı bankaların ülke bankacılık sektörü üzerine farklı etkileri olmakla birlikte, bu çalışmada yabancı bankaların ülke bankacılık sektörünün kârlılığı üzerindeki etkisi test edilecektir. Bankaların aktif kârlılık oranını temsil etmek üzere literatürde (Classens, 2001; Balaj, 2010; Azam, 2012; Arshad, 2012; Baltac1, 2012) siklıkla kullanılan ROA kullanılacaktır.

Test edecek model aşağıdaki gibidir:

$$
\text { ROAit }=\alpha_{\text {it }}+\beta_{1} \mathrm{BUY}_{\text {it }}+\beta_{2} \mathrm{YBA}_{\text {it }}+\beta_{3} \mathrm{ENF}_{\text {it }}+\beta_{4} \mathrm{BMB}_{\text {it }}+\beta_{5} \mathrm{NFM}_{\mathrm{it}}+\varepsilon_{\text {it }}
$$

Burada;

$$
\begin{aligned}
& i=1,2,3,4,5,6 \quad \text { (Ülkeler) } \\
& t=2006,2007, \ldots . .2016 \quad \text { (Y1llar) şeklindedir. }
\end{aligned}
$$

Tablo 2'de çalışmada kullanılacak model değişkenleri hakkında açıklamalar verilmiştir. 
Çalışmada kullanılan değişkenlere ait veriler World bank ve IMF'in ilgili veri tabanlarından elde edilerek kullanılmıştır. İlgili değişkenlerin bir önceki yıla göre değişimleri hesaplanarak analizde kullanılacaktır.

Tablo 2: Çalışmada Kullanılan Değişkenler ve Açıklamaları

\begin{tabular}{|c|c|c|c|}
\hline Değişken & Açıklama & Kaynak & Referans \\
\hline ROA & $\begin{array}{l}\text { Aktif Kârlılı̆ğ }=\text { Net } \\
\text { Kâr/ Toplam Aktif }\end{array}$ & $\begin{array}{l}\text { World } \\
\text { Development } \\
\text { Indicators }\end{array}$ & $\begin{array}{l}\text { Naceur ve } \text { Goaied (2001); } \\
\text { Pasiouras ve Kosmidou } \\
(2007)\end{array}$ \\
\hline BUY & 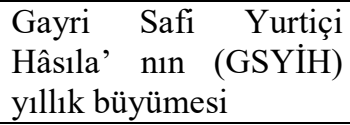 & IMF & $\begin{array}{l}\text { Weller (2001); Cottarelli vd. } \\
\text { (2005); Oluitan (2009) }\end{array}$ \\
\hline YBA & $\begin{array}{l}\text { Yabancı Banka Aktif / } \\
\text { Sektör Aktif Toplamı }\end{array}$ & $\begin{array}{l}\text { World } \\
\text { Development } \\
\text { Indicators } \\
\end{array}$ & $\begin{array}{l}\text { Clarke, vd. } \quad(2001) ; \\
\text { Dudzevičiūte (2005); Brown } \\
(2006)\end{array}$ \\
\hline ENF & $\begin{array}{l}\text { Y1llık Tüketici } \text { Fiyat } \\
\text { Enflasyonu artışı }\end{array}$ & IMF & $\begin{array}{l}\text { Maurer (2008); Brown } \\
(2006) \text {; Clarke, vd. }(2006)\end{array}$ \\
\hline BMB & $\begin{array}{l}\text { (Banka Mevduatları/ } \\
\text { GSYIH) x } 100\end{array}$ & $\begin{array}{l}\text { World } \\
\text { Development } \\
\text { Indicators }\end{array}$ & $\begin{array}{l}\text { Weller (2000); } \\
\text { Yagcilar (2010) }\end{array}$ \\
\hline NFM & $\begin{array}{l}\text { Net Faiz Marjı }(\text { NFM)= } \\
\text { (Varlıklardan } \\
\text { Edilen Elde } \\
\text { Borçlar için Ödenen } \\
\text { Faizler) / } \\
\text { Varlıklar }\end{array}$ & Worldbank & $\begin{array}{l}\text { Raharjo ve diğ., (2014); } \\
\text { Hamadi ve Awdeh, (2012) }\end{array}$ \\
\hline
\end{tabular}

Bağımsız değişkenin bağımlı değişkenler üzerindeki etkisini tek bir finansal gösterge ile açıklamak sağlıklı ve gerçekçi olamayacağı için bağımsız değişken ile beraber kontrol değişkenleri de modele eklenerek çalışmanın daha tutarlı olması amaçlanmıştır.

\section{Araştırmanın Bulguları}

Tablo 3'te panel veri analizinde kullanılan değişkenlere ait tanımlayıcı istatistiki bilgilere yer verilmiştir.

Tablo 3: Tanımlayıcı İstatistikler

\begin{tabular}{|l|c|c|c|c|c|c|}
\hline & ROA & BMB & BUY & ENF & NFM & YBA \\
\hline Ortalama & 2.377 & -0.065 & 1.419 & -0.464 & -0.035 & -0.067 \\
\hline Maximum & 22.291 & 0.949 & 7.450 & 13.191 & 7.696 & 5.153 \\
\hline Minimum & -4.559 & $-1,869$ & -6.079 & -13.068 & -8.476 & -4.309 \\
\hline Standart sapma & 4.257 & 0.438 & 2.474 & 3.829 & 2.701 & 1.261 \\
\hline Gözlem SayıSı & 66 & 66 & 66 & 66 & 66 & 66 \\
\hline
\end{tabular}

Tablo 3'te verilen istatistiklere bakıldığında veriler içinde en fazla dalgalanma büyüme değişkeninde gözlemlenmiştir. En az dalgalanma ise banka mevduatları değişkeninde gözlemlenmiştir. 
Yabancı Bankaların Bankacılık Sektörü Aktif Kârlllı̆̆ı Üzerindeki Etkileri: BRICS-T Örneği

Tablo 4: Değişkenler Arasindaki Korelasyon

\begin{tabular}{|l|c|c|c|c|c|}
\hline & BMB & BUY & ENF & NFM & YBA \\
\hline BMB & 1 & & & & \\
\hline BUY & -0.41 & 1 & & & \\
\hline ENF & 0.10 & -0.11 & 1 & & \\
\hline NFM & -0.07 & -0.12 & -0.25 & 1 & \\
\hline YBA & 0.01 & 0.08 & 0.03 & -0.02 & 1 \\
\hline
\end{tabular}

Tablo 4'te değişkenler arasındaki korelasyon matrisi görülmektedir. Analizin güvenilir sonuç vermesi için değişkenler arasında yüksek korelasyon katsayısının olmaması gerekmektedir. Uludağ ve Gökmen (2011)'in çalışmalarında belirtildiği üzere, korelasyon katsayısı 0.75 'den büyük olmadıkça, değişkenler arasında çoklu doğrusal bağlantı sorunu regresyon analizi için önem teşkil etmez. Bu bağlamda Tablo 4 incelendiğinde değişkenler arasında önemli derecede (\% $\% 5$ 'den yüksek bir korelasyon) korelasyon katsayısı tespit edilmemiştir.

Baltagi-Li (1995) ile Wooldridge (2002) tarafından yapılan çalışmalarda belirtilen açıklama kabul edilerek panel veri analizi yapılması sonucunda elde edilen hata terimlerinin değişen varyans ve otokorelasyon katsayıları sabit etkiler modeli kullanılarak tahmin edilmiştir. Hata terimlerinin değişen varyans özelliği gösterip göstermediği Wald testi, hata terimleri arasında otokorelasyon olup olmadığı ise Wooldridge testi kullanılarak araştırılmıştır.

Söz konusu testte sinanan hipotezler şu şekildedir:

$\mathrm{H}_{0}$ : "Otokorelasyon Yoktur"

$\mathrm{H}_{1}$ : "Otokorelasyon Vardır"

Tablo 5: Otokorelasyon Testi Sonuçları

\begin{tabular}{|l|l|}
\hline Test & İstatistik Değeri \\
\hline Wooldridge testi & 0.216 \\
\hline Wooldridge Testi P değeri & 0.6618 \\
\hline
\end{tabular}

Bağımsız değişkenlerin bağımlı değişkeni açıklamasını gösteren etkisini daha net ve gerçekçi değerler üzerinden yorumlayabilmek için, hata terimlerinin otokorelasyon ve değişen varyans özelliği gösterip göstermediği incelenmektedir. Söz konusu test sonuçları ve istatistik değerleri Tablo 5'de sunulmuştur. Burada yapılan test sonucuna göre otokorelasyon olmadığını ifade eden sifir hipotezi kabul edilerek, alternatif hipotez reddedilmiştir. Dolayısıyla modelde otokorelasyon sorunu bulunmamaktadır.

Araştırma modelinin yansız ve etkin olabilmesi için ardışı bağımlılık ve değişen varyans sorununun olmaması gerekmektedir. Söz konusu testte sınanan hipotezler şu şekildedir:

$\mathrm{H}_{0:}$ " "Değişen Varyans Yoktur"

$\mathrm{H}_{1}$ : "Değişen Varyans Vardır" 
Tablo 6: Değişen Varyans Testi Sonuçları

\begin{tabular}{|c|c|}
\hline Test & İstatistik Değeri \\
\hline Breusch-Pagan testi & 1.290 \\
\hline Breusch-Pagan Testi P değeri & 0.2563 \\
\hline
\end{tabular}

Değişen varyans test sonuçları ve istatistik değerleri Tablo 6'da sunulmuştur. Buna göre, $0.25>0.05$ olduğu için bankaların aktif kârlılığı modeli ile tahminden elde edilen sonuçlara göre modelde değişen varyans sorununun olmadığı görülmüştür. Yapılan test sonucunda $\mathrm{H}_{0}$ hipotezi kabul edilerek, $\mathrm{H}_{1}$ hipotezi reddedilmiştir.

Çalışmada, bu aşamada analize dâhil olan panel veri setinde, yatay kesit bağımlılığının belirlenmesi için, ele alınan örneklemde $(T>N)$ olduğundan Berusch-Pagan (1980) tarafindan geliştirilen $\mathrm{CD}_{\mathrm{LM}}$ testi yapılmıştır.

Söz konusu testte sinanan hipotezler şu şekildedir:

$\mathrm{H}_{0}$ : "Yatay Kesit Bağımlılı̆̆ Yoktur"

$\mathrm{H}_{1}$ : "Yatay Kesit Bağımlığı Vardır"

$\mathrm{Bu}$ test yardımıyla yatay kesit birimlerinin birbiriyle bağımlı olup olmadıkları, diğer bir ifadeyle seriye belli bir şok gelmesi durumunda tüm yatay kesit birimlerinin söz konusu şoktan aynı derece etkilenip etkilenmediği tespit edilmektedir. Söz konusu teste ilişkin sonuçlar ise Tablo 7'de verilmiştir.

Tablo 7: Yatay Kesit Bağımlılık Testi (LM) Sonuçları

\begin{tabular}{|c|c|}
\hline Test & İstatistik Değeri \\
\hline $\mathrm{CD}_{\mathrm{LM}}$ testi & -1.230 \\
\hline $\mathrm{CD}_{\mathrm{LM}}$ Testi P değeri & 0.288 \\
\hline
\end{tabular}

Tablo 7'de ki LM test sonuçlarına göre, $0.288>0.05$ olduğu için yatay kesit bağımlılığı yoktur. Yatay kesit bağımlılığının olmadığına ilişkin boş hipotez istatistiki olarak kabul edilmektedir. Elde edilen bu sonuç çalışmada kullanılan panel veri setinde yatay kesit bağımlılı̆̆ının olmadığına işaret etmektedir. Analizde, yatay kesit bağımlılığı olmadığı için 1. nesil birim kök testleri olarak adlandırılan tahmincilerden, Levin, Lin ve Chu (2002) panelde yer alan tüm birimlerin birinci dereceden kısmi otokorelasyona sahip olduğunu varsayar. LLC panel birim kök testlerinde ortak bir birim kökün varlığına dair boş hipotez test edilirken Levin ve diğerleri (2002) tarafından geliştirilen LLC (Levin-Lin ve Chu) birim kök testi uygulanmıştır.

Çalışmada kullanılan modellerde yer alan değişkenlerin birim kök test sonuçları Tablo 8'de verilmiştir. 
Yabancı Bankaların Bankacılık Sektörü Aktif Kârlllı̆̆ı Üzerindeki Etkileri: BRICS-T Örneği

Tablo 8: Birim Kök Testi Sonuçları

\begin{tabular}{|c|c|c|c|}
\hline & \multicolumn{3}{|c|}{ Levin, Lin \& Chu } \\
\hline Değişkenler & Sabit & Sabit + Trend & Sonuç \\
\hline ROA Düzey & $\begin{array}{c}-6.0230 \\
(0.000)^{*}\end{array}$ & $\begin{array}{l}-7.6089 \\
(0.000)^{*}\end{array}$ & $\mathrm{I}(0)$ \\
\hline ROA 1.fark & $\begin{array}{l}-6.1140 \\
(0.000)^{*}\end{array}$ & $\begin{array}{c}-1.8956 \\
(0.029)\end{array}$ & $\mathrm{I}(0)$ \\
\hline GDP Düzey & $\begin{array}{l}-11.2796 \\
(0.000)^{*}\end{array}$ & $\begin{array}{l}-13.5302 \\
(0.000)^{*}\end{array}$ & $\mathrm{I}(0)$ \\
\hline GDP 1.Fark & $\begin{array}{l}-15.9175 \\
(0.000)^{*}\end{array}$ & $\begin{array}{l}-13.4914 \\
(0.000)^{*}\end{array}$ & $\mathrm{I}(0)$ \\
\hline BMB Düzey & $\begin{array}{l}-2.5322 \\
(0.005)^{*}\end{array}$ & $\begin{array}{l}-2.2045 \\
(0.013)\end{array}$ & $\mathrm{I}(0)$ \\
\hline BMB 1. Fark & $\begin{array}{l}-5.3999 \\
(0.000)^{*}\end{array}$ & $\begin{array}{l}-4.7661 \\
(0.000)^{*}\end{array}$ & $\mathrm{I}(0)$ \\
\hline ENF Düzey & $\begin{array}{l}-6.0345 \\
(0.000)^{*}\end{array}$ & $\begin{array}{l}-7.6369 \\
(0.000)^{*}\end{array}$ & $\mathrm{I}(0)$ \\
\hline ENF 1. Fark & $\begin{array}{l}-7.7335 \\
(0.000)^{*}\end{array}$ & $\begin{array}{l}-10.3336 \\
(0.000)^{*}\end{array}$ & $\mathrm{I}(0)$ \\
\hline NFM Düzey & $\begin{array}{l}-4.1194 \\
(0.000)^{*}\end{array}$ & $\begin{array}{l}-4.1042 \\
(0.000)^{*}\end{array}$ & $\mathrm{I}(0)$ \\
\hline NFM 1. Fark & $\begin{array}{l}-14.9855 \\
(0.000)^{*}\end{array}$ & $\begin{array}{l}-6.3602 \\
(0.000)^{*}\end{array}$ & $\mathrm{I}(0)$ \\
\hline YBA Düzey & $\begin{array}{l}-1.2549 \\
(0.000)^{*}\end{array}$ & $\begin{array}{l}-3.9346 \\
(0.000)^{*}\end{array}$ & $\mathrm{I}(0)$ \\
\hline YBA 1. Fark & $\begin{array}{l}-4.8652 \\
(0.000)^{*}\end{array}$ & $\begin{array}{l}-5.8293 \\
(0.000)^{*}\end{array}$ & $\mathrm{I}(0)$ \\
\hline
\end{tabular}

Not: * değeri \% 1 düzeyinde anlamlı farklılığı ifade etmektedir.

Serilerin durağanlık seviyesi için yapılan bu testte verilerin Levin, Lin \& Chu testine göre $(\mathrm{I}(0))$ düzeyinde durağan olduğu tespit edilmiştir.

Panel veri modelleri, zaman etkileri veya birim etkilerini veya her ikisini inceleyerek, gözlemlenebilecek veya gözlemlenemeyecek heterojenliği veya bireysel etkileri araştırma amacına dayanmaktadır. Bu etkiler sabit etkili veya rassal etkili olabilmektedir. Sabit etkiler modeli (fixed), kesişim noktalarının (intercepts) zaman dilimi boyunca ya da birimler arası farklı olup olmadıklarını incelerken, rassal etkiler modeli (random), birimler arası veya zaman dilimi boyunca hata varyansı bileşenlerinin birbirleri ile aralarındaki farkları araştırmaktadır (Park, 2011: 7).

Birim kök testi yapıldıktan sonra ise, serilerimizin düzey seviyede durağan çımasıyla birlikte analize sabit etkiler modeli ve rassal etkiler modelinden hangisinin daha uygun ve geçerli olacağı Hausman testi sonucu karar verilecektir. Tablo 10'da yapılan test sonuçlarına göre en uygun modelin rassal etkiler panel veri modeli olduğuna karar verilmiştir. 
Tablo 9: Hausman Test Sonuçları

\begin{tabular}{|l|l|r|r|}
\hline Test & İstatistik & P-Değeri & Sonuç \\
\hline Hausman & 0.54 & 0.9905 & Rassal \\
\hline
\end{tabular}

Tablo 9'da yapılan Hausman testinin sonucunda p>0.05 olduğu için model seçiminde rassal etkili panel veri modeli kullanılacaktır. Aşağıda yapılan analizde rassal etkili yönteme göre regresyon analizi yapılarak sonuçları Tablo 10 'da gösterilmiştir.

Regresyon sonuçları aşağıdaki tabloda verilmiştir:

Tablo 10: Panel Veri Analiz Sonuçları

\begin{tabular}{|l|c|}
\hline \multicolumn{2}{|c|}{$\begin{array}{c}\text { Bağımlı Değişken } \\
\text { ROA }\end{array}$} \\
\hline \multirow{2}{*}{ LOGBMB } & -0.004 \\
& {$[\mathbf{0 . 8 3 0 ]}$} \\
\hline \multirow{2}{*}{ LOGENF } & 0.237 \\
& {$[\mathbf{0 . 1 5 1 ]}$} \\
\hline \multirow{2}{*}{ LOGGDP } & 0.014 \\
& {$[\mathbf{0 . 2 5 4}]$} \\
\hline \multirow{2}{*}{ LOGNFM } & 0.231 \\
& {$[\mathbf{0 . 0 0 0}]^{* * *}$} \\
\hline \multirow{2}{*}{ LOGYBA } & 0.046 \\
& {$[\mathbf{0 . 0 6 0}]^{*}$} \\
\hline Gözlem sayıs1 & $\mathbf{6 6}$ \\
\hline R & $\mathbf{0 . 7 2}$ \\
\hline F Testi & $\mathbf{4 5 . 1 8}$ \\
\hline F testi olas1lik D. & $\mathbf{0 . 0 0 0}$ \\
\hline Kullanılan Yöntem & Rassal \\
\hline
\end{tabular}

Not: Tabloda italik semboller katsayı değerlerini, köşeli parantezli değerler ise anlamlılık değerlerini göstermektedir. $* \% 10, * * 05$ ve $* * * \% 1$ düzeyinde anlamlı farklılığ ifade etmektedir.

Yukarıdaki tabloda rassal etki test sonuçları gösterilmiştir. $\mathrm{R}^{2}$, modeldeki bağımsız değişkenlerin bağımlı değişkeni açıklama gücünü göstermektedir. 0.72 ile değişkenlerin açıklama gücünün yüksek olduğu görülmektedir.

Yapılan analiz sonuçlarına göre ROA ile yabancı banka aktifleri arasında $\% 10$ düzeyinde pozitif ve anlamlı ilişki tespit edilmiştir. Yabancı banka aktiflerindeki her \%1'lik artı̧̧ bankaların aktif karlılığı değişkeni üzerinde $\% 0.046$ 'lik bir artışa yol açmaktadır. Yabancı banka aktiflerin sektör aktiflerine oranı ile banka aktif karlılığı arasında pozitif ve anlamlı ilişki olduğu tespit edilmiştir.

Enflasyonun artması ile birlikte bankaların aktif karlılığı arasında negatif bir ilişkinin çıkması beklenmektedir. Yüksek enflasyonun olduğu durumlarda, tüketimlerin ertelenmesi ve banka ile olan işlemlerin azalması nedeniyle banka karlarında azalışın olması normal karşılanabilecek bir durumdur. Ancak, test 
sonuçlarında enflasyon ile banka aktif karları arasında da anlamsız ilişki çıktığı görülmüştür.

Karlılık ile ilgili olarak ele alınan iki değişken arasında (ROA ve NFM) $\% 1$ düzeyinde 0.231 katsayısı ile anlamlı ve pozitif ilişki olduğu görülmektedir. Net faiz marjındaki her \%1'lik artış bankaların aktif karlılığı değișkeni üzerinde $\% 0.231^{\prime}$ lik bir artışa yol açmaktadır. Net faiz marjının artması durumunda banka aktif karlarında da artışlar olacaktır. Net faiz marjının artması, bankaların düşük faiz ile borçlanması, borçlandığı fonları daha yüksek faiz oranı ile borç vermesinden dolayı daha fazla kâr elde etmesi beklenmektedir. Bu nedenlerden dolayı net faiz marjı ile banka aktif kârlılığı arasında pozitif ilişkinin çıkması olağandır. Net faiz marjı ile banka aktif karlılı̆̆ arasında pozitif ve anlamlı ilişki olduğu tespit edilmiştir. Arshad (2012) tarafindan yapılan çalışmada elde ettikleri bulgular ile çalı̧̧mamızda elde edilen bulgular birbirini desteklemektedir.

Yine ROA ile GDP arasında anlamsız ilişki çıtı̆̆ğ görülmektedir. GDP ile bankaların aktif kârlılığı arasında pozitif ilişki sonucu beklenmektedir. Ülkelerin bankacılık sisteminde büyüme trendinin devam etmesi halinde ekonomik büyümeye bağlı olarak banka karlarında da artış yaşanması muhtemeldir. Büyüme ile beraber bankaların daha fazla fon bulma imkânının artacă̆ı, bu fonların değerlendirilerek daha fazla kâra dönüştürebilmeleri tahmin edildiği için olumlu ilişki çıkması beklenmiştir. Fakat analiz sonucunda ROA ve GDP arasında anlamsız ilişki olduğu tespit edilmiştir. Banka aktif karlılığı ile büyüme arasında anlamlı bir ilişki tespit edilememiştir.

\section{Sonuç}

20. yüzy1l, küreselleşmenin etkilerinin tüm piyasalarda hem ekonomik hem de teknolojik yönden önemli ölçüde görüldüğ̈̈ bir dönem olarak kabul edilmektedir. Küreselleşme ile birlikte yaşanan gelişmeler, toplumsal, kültürel, sosyal ve en önemlisi de ekonomik açıdan toplumları etkileyebilmektedir. Toplumlar arasındaki sosyal ve kültürel farklılıklar azalmış ve dünya, ekonomik anlamda tek bir pazar haline gelmiştir. Söz konusu gelişmelerden finansal piyasalarda nasibini almıştır.

Ülkelerin ekonomik büyümesini sağlayan en önemli faktörlerin başında finansal sektörün, finansal sektörün en önemli aktörünün ise bankacilık biriminin olduğunu söylemek mümkündür. Bankacılık sektörünün istikrarlı işlemesi, ülkedeki ekonomik performans, istikrar ve gelişmişlik için çok önemli bir rol üstlenmektedir. Küreselleşme ve finansal entegrasyon sürecinde bankacılık sektörü yabancı iştiraklerin artışı ile karşı karşıyadır. Gelecek yıllarda, yabancı bankaların sektör üzerindeki etkilerinin daha da belirgin olacağı öngörülmektedir.

Yabancı bankaların reel sektör ve rekabet üzerindeki etkileri, özellikle gelişmekte olan piyasalarda faaliyet gösteren yabancı bankaların etkileri literatürde tartışılan bir konudur. Gelişmiş ülkelerden gelişmekte olan ülkelere 
doğru kayan yabancı sermaye girişine paralel olarak, gelişmekte olan ülkelerde bulunan yerli bankalarda, farklı ülkelerin bankacılık sektörüne yabancı banka olarak yönelmişlerdir. Küresel sermayeli yabancı bankaların gelişmekte olan ülkelerin bankacılık sektörlerine dâhil olması ile, gelişmekte olan ülkelerin bankacılık sektörlerindeki rekabet düzeyi artmıştır. Bundan dolayı eş zamanlı olarak, bankacılık sektöründeki ürün çeşitliliği çoğalmıştır. Gelişmekte olan ülkelerin piyasalarına giren yabancı bankalar, yerel bankacılık sektöründeki rekabeti uluslararası boyuta taşımıştır.

Tüm bunlardan hareketle bu çalışmada, BRICS ülkeleri ile Türkiye verilerinden hareketle yapılan panel veri analizinde, bağımlı değişken olan banka aktif kârlılığı ile bağımsız değişkenlerden olan banka mevduatları, net faiz marjı ve yabancı bankaların aktifleri arasında anlamlı ilişkiler olduğu ortaya çıkmıştır. Yani banka mevduatlarında oluşacak artış ve net faiz marjının daralması ile reel sektöre verilecek kredilerde artış meydana geleceği tespit edilmiştir. Banka aktif karlılığında ise yabancı banka aktiflerinde artış meydana geldiği durumlarda ve net faiz marjının artması durumlarında bankaların aktif karlılıklarında artış meydana geleceği analiz sonucunda tespit edilmiştir (Hantapong, 2005; Boadi, 2015).

Bir ülkenin bankacılık sisteminin, yabancı bankaların girişinden fayda sağlayabilmesi için yabancı bankaların olası olumsuz etkilerini tahmin etmeleri faydalı olacaktır. Yabancı banka aktiflerinin artması ile banka karlarında yaşanan artışlar nedeniyle, yabancı sermayeli bankaların, bulunduğu ülkedeki bankacılık sektörüne olumlu bir etkisi olduğu ortaya konulmuştur. Buradan hareketle, gözlemlenen ülkeler özelinde gelişmekte olan tüm ülkelerde bankacılık sektörünün geliştirilmesi amacı ile sektörün, yabancı bankalar tarafindan kullanılan alt yapıya ve teknolojiye sahip olmaları gerekmektedir.

İlerde, yabancı bankalarla ilgili yapılacak çalışmalarda, bankacılık sektörü kârlılığını etkileyebilecek diğer içsel ve dışsal değişkenlerle farklı modeller denenebileceği gibi yabancı bankaların ülke ekonomisi üzerindeki etkileri ve reel sektör kredileri ile yabancı bankaların aktifi ilişkisi de araştırılabilecek konular arasındadır.

\section{Kaynaklar}

Aktaş, H. ve Kargın, M. (2007). Türk Bankacılık Sektöründeki Yabancı ve Ulusal Bankaların Finansal Oranlar Açısından Karşılaştırılması. Celal Bayar Üniversitesi I.I.I.B.F. Yönetim ve Ekonomi Dergisi, 14(2), 31-45.

Anderson, R. W. ve Chantal, K. (1998). Transition Banking. Financial Development of Central and Eastern Europe. Clarendon Press. Oxford, $\mathrm{WP} / 06 / 189$.

Ay, H. (2005). Yatırım Teşviklerinin Sabit Sermaye Yatırımları Üzerindeki Etkisi. Selçuk Üniversitesi Karaman İktisadi ve İdari Bilimler Dergisi, 2(5), 176-180. 
Yabancı Bankaların Bankacıllk Sektörü Aktif Kârllllğı Üzerindeki Etkileri: BRICS-T Örneği

Apak, S. ve Aykut, T. (2007). Bankacılık Kredileri ve Yabancı Sermaye Yatırımlarının Politik Riske Göre Değerlendirilmesi: Türkiye Örneği. Muhasebe ve Finansman Dergisi, 33, 31-43.

Arshad, R. (2012). Impact of Foreign Bank's Profitability on Domestic Bank's Earnings in BRIC. Umeå School of Business and Economics, Spring semester, Doktora Tezi.

Baltacı, N. (2011). Geçis Ekonomilerinde Yabancı Bankaların Piyasaya Girmesinin Kredi Tahsisine Etkisi: 1995 Sonrası Karş̧laştırmalı Bir Analiz, Dumlupınar Üniversitesi Sosyal Bilimler Enstitüsü, Doktora Tezi.

BDDK (2018). Bankalarımız 2017, 327, 15-50.

Boadi, I. (2015). Effects of Foreign Banks Entry on the Operations of Domestic Banks Empirical Evidence from Ghana. International Journal of Business and Management, 10(12), 54-71.

Bumin, M. (2007). Türk Bankacılık Sektöründe Yabancı Bankalar, Ankara: Turhan Kitabevi.

Claessens, S., Demirgüç, K. A. ve Huizinga, H. (2001). How Does Foreign Entry Affect Domestic Banking Markets? Journal of Banking and Finance, 25, 891-911.

Çakar, V. (2003). Yabancı Sermayeli Banka Girişleri ve Ulusal Bankacılık Sektörleri Üzerindeki Etkileri, Uzmanlık Yeterlilik Tezi.

Çamoğlu, M. S. ve Akınc1, M. (2012). Türkiye'de Sektörel Banka Kredilerinin Gelișimi: Bir Zaman Serisi Analizi. Celal Bayar Üniversitesi Yönetim ve Ekonomi Dergisi, 19(1), 50-75.

Dages, B. G., Goldberg, L. ve Kinney, D. (2000). Foreign and Domestic Bank Participation in Emerging Markets: Lessons from Mexico and Argentina. Federal Reserve Bank of New York Economic Policy Review, 6(3), 1735.

Demirci, S. (2017). İmalat Sanayi Sektöründe Kârlılı̆̆ın Belirleyicileri: TCMB Sektör Bilançolarıyla Panel Veri Analizi (1996-2015). Ege Akademik Bakış Dergisi, 17(3), 381-394.

Erdönmez, P. A. (2004). Finansal Krizler Sonrası Gelişmekte Olan Ülkelerde Yabancı Bankalar. T.B.B. Bankacılık ve Araştırma Grubu, Bankacılar Dergisi, 1, 50-75.

Goldberg, L. S. (2004). Financial-Sector Foreign Direct İnvestment And Host Countries: New And Old Lessons. FRB of New York Staff Report, 10, 170-190.

Ekşi, H. İ., Taşdemir, A. ve Hacıevliyagil, N. (2016). Mülkiyet Yapısının Finansal Oranlar Üzerindeki Etkisi: Mevduat Bankalarında Uygulama. Kastamonu Üniversitesi, İktisadi ve İdari Bilimler Fakültesi Dergisi, 12, 540-555.

McKinnon, R. I. (1988). Financial Liberalisation in Retrospect: Interest Rate Policies in LDCs. The State of Development Economics, Oxford: Basil Blackwell, 3, 1-39. 
Okuyan, H. ve Karataş, Y. (2017). Türk Bankacılık Sektörünün Kârll11k Analizi. EGE Akademik Bakış Dergisi. 17(3), 395-406.

Özsoylu, A. F. ve Algan, N. (2011). Dünya Ekonomisinin Yeni Aktörleri: BRICBrezilya. Rusya. Hindistan. Çin, İstanbul: Karahan Kitabevi.

Sanyal, P. ve Shankar, R. (2011). Ownership, Competition, And Bank Productivity: An Analysis of Indian Banking in the Post-Reform Period. International Review of Economics and Finance, 20, 225-247.

Şahözkan, B. C. (2003). Banka Birleşmeleri. Türkiye Bankalar Birliği Dergisi, 233, 250-265.

Saovanee, C. (2005). Comparative Study of Domestic and Foreign Bank Performance in Thailand: The Regression Analysis, Economic Change and Restructuring, 38(1), 63-83.

TBB Araştırma Grubu (2005). Türkiye'de Yabancı Bankalar. Bankacılar Dergisi, 52, 1-50.

https://www.ineteconomics.org/perspectives/blog/brics-to-play-a-leading-rolein-driving-future-global-economic-growth 